\title{
Radical Scavenging and Inhibition of Platelet Function by a Polyphenol- Rich Fraction from Salvia miltiorrhiza Bunge
}

\author{
Seun-Ah Yang ${ }^{1}$, Nam-Kyung $\mathrm{Im}^{2}$, Young-Joo $\mathrm{Ji}^{2}$, Dong-Chan $\mathrm{Yoo}^{3}$, Kwang-Hwan Jhee ${ }^{3}$ and \\ In-Seon Lee*,2
}

${ }^{I}$ The Center for Traditional Microorganism Resources (TMR); ${ }^{2}$ Department of Food Science and Technology Keimyung University, Daegu 704-701, South Korea; ${ }^{3}$ Department of Applied Chemistry, Kumoh National Institute of Technology, Gumi 730-701, South Korea

\begin{abstract}
A diet rich in polyphenols has previously been shown to be associated with a lower risk for cardiovascular disease. Specifically, inhibition of platelet hyperactivation by polyphenols decreases platelet-dependent thrombosis, reducing the risk for cardiovascular disease. However, whether polyphenols in Salvia miltiorrhiza Bunge (SMB) affect platelet functions has not been clearly determined. Here, we investigated the effects of methanol and ethyl acetate (EtOAc) extracts from SMB on free radical scavenging activities, and platelet aggregation and adhesion. We found that the EtOAc fraction was the most effective at scavenging 1,1-diphenyl-2-picrylhydrazyl (DPPH) and 2,2'-azinobis(3ethylbenzothiazoline-6-sulfonic acid) (ABTS) free radicals (concentration for 50\% reduction, $\mathrm{RC}_{50}=2.4 \pm 1.5$ and $27.9 \pm$ $1.4 \mu \mathrm{g} / \mathrm{mL}$, respectively), and that, especially for DPPH radicals, the EtOAc fraction showed better scavenging activity than butylated hydroxyanisole $\left(\mathrm{BHA}, \mathrm{RC}_{50}=5.5 \pm 0.1 \mu \mathrm{g} / \mathrm{mL}\right.$ ). Measurements with a turbidimetric aggregometer revealed that the EtOAc fraction was the most potent inhibitor of ADP- and collagen-induced rat platelet aggregation. In addition, the methanol and EtOAc fraction dose-dependently inhibited thrombin-stimulated platelet adhesion to collagen or fibrinogen. Collectively, these results suggest that the polyphenol-rich EtOAc fraction from SMB can reduce platelet hyperactivation by scavenging free radicals. Thus, the EtOAc fraction of SMB is a potential source of inhibitors of plateletdependent thrombosis.
\end{abstract}

Keywords: Salvia miltiorrhiza Bunge, adhesion, platelet aggregation, antioxidant, polyphenol.

\section{INTRODUCTION}

Platelets, which are key players in thrombosis, are the smallest enucleated blood cells derived from megakaryocytes. These cells respond to a variety of activators, including thrombin, epinephrine, serotonin, ADP, thromboxane $\mathrm{A}_{2}$ and collagen, which can affect platelet adhesion, shape, and aggregation as well as their secretion of storage granules [1, 2]. Platelet hyperactivity at the site of injury or in atherosclerotic vessel walls plays a major role in thrombosis and the pathogenesis of cardiovascular diseases, and inhibition of platelets function decreases thrombosis and therefore heart disease [3].

Given the importance of thrombosis in cardiovascular disorders, natural products, for example, extracts from Ginkgo biloba [4], garlic [5], and onion [6], as well as omega-3 fatty acids from fish oil [7], have been screened for anti-platelet activity. Likewise, flavonoid-rich foods such as grapes juice [8] and cocoa [9], as well as catechin, epicatechin, and procyanidine have been shown to modify platelet function [10]. In general, the in vitro inhibitory effects of dietary antioxidants and the flavonoids on platelet function have been extensively investigated [11].

\footnotetext{
*Address correspondence to this author at the Department of Food Science and Technology Keimyung University, Daegu 704-701, South Korea; Fax: +8253580 6447; E-mail: inseon@kmu.ac.kr
}

Salvia miltiorrhiza Bunge (SMB), a popular traditional Chinese medicinal plant, has been used extensively not only in China, but also in Korea for the treatment of coronary heart disease, cerebrovascular disease, and inflammation, and it is cytotoxic to human tumor cell lines $[12,13]$. SMB is mainly used as a decoction in traditional Chinese medicine. Thus, much attention has recently been focused on polyphenols, which are the biologically active water-soluble components. The putative active components are salvianolic acid B, danshensu, lithospermic acids, protocatechuic acid, and rosmarinic acid [14]. In recent years, an increasing number of phenolic components from the water-soluble fraction of SMB have been reported to prevent cardiovascular disease.

Despite these findings, the relationship between the antioxidant activity and the effects of platelet function of various SMB extracts has not been clarified. Thus, in the current study, we investigated the antioxidant and anti-platelet activities of different solvent fractions of SMB. The results should help in the production of functional foods with antioxidant and anti-platelet function.

\section{MATERIALS AND METHODS}

\section{Materials}

SMB roots were purchased from a Chinese drug store in Daegu, Korea. DPPH, ABTS, dimethyl sulfoxide (DMSO), fibrinogen, thrombin, bicinchoninic acid, HEPES and $\mathrm{NaCl}$ were purchased from Sigma-Aldrich (Sigma, St. Louis, MO, USA). Collagen and ADP were obtained from Chrono-Log 
(Chrono-Log Co., Ltd., Havertown, PA. USA). EtOAc, hexane, chloroform, methanol, and butanol were purchased from Duksan (Duksan Pure Chemical Co., Ltd., Ansan, Kyungido, Korea).

\section{Extraction and Fractionation of SMB}

SMB $(1 \mathrm{~kg})$ was extracted three times with $10 \mathrm{~L}$ of $80 \%$ methanol at room temperature for $24 \mathrm{~h}$. The extract was filtered through No. 3 filter paper (Whatman, Maidstone, UK), and the combined filtrate was concentrated in a rotary evaporator (EYELA NVC-2000; Tokyo Rikakikai Co. Ltd., Tokyo, Japan) at $55^{\circ} \mathrm{C}$ and then freeze-dried, providing $396.2 \mathrm{~g}$ of methanol extract $(39.6 \%$ yield). The methanol extract $(100 \mathrm{~g})$ was resuspended in distilled water and sequentially partitioned into hexane (0.65 g), chloroform (13.84 g), EtOAc (1.78 g), butanol (2.79 g), and water (57.04 g) fractions. The organic solvent fractions were concentrated to dryness by rotary evaporation at $55^{\circ} \mathrm{C}$, and the water fraction was freeze-dried.

\section{DPPH Radical Scavenging Activity}

Radical activities were determined using DPPH as a free radical as described by Moreno et al. [15] with some modifications. Briefly, in each well of a 96-well plate, $160 \mu \mathrm{L}$ of various concentrations of sample in methanol were added to $40 \mu \mathrm{L}$ of $0.15 \mathrm{mM}$ DPPH in methanol. After a 30-min incubation in the dark at room temperature, the decrease in absorbance was measured at $517 \mathrm{~nm}$. Methanol was used as the blank solution, and DPPH solution without any added sample extract served as a control. The radical scavenging activity was calculated from a standard curve of known concentrations of BHA. The concentration required for a $50 \%$ reduction of DPPH levels after $30 \mathrm{~min}\left(\mathrm{RC}_{50}\right)$ was calculated from the reduction in the absorbance at $517 \mathrm{~nm}$. The experiment was performed in triplicate.

\section{ABTS Radical Scavenging Activity}

ABTS radical scavenging activity was measured by the ABTS cation decolorization assay as described by Re et al. [16]. Briefly, $14 \mathrm{mM}$ ABTS was mixed with an equal volume of $4.95 \mathrm{mM}$ potassium persulfate. After $24 \mathrm{~h}$ incubation at room temperature in the dark, the resulting ABTS radical solution was diluted appropriately with phosphate-buffered saline. Next, in each well of a 96-well plate, $20 \mu \mathrm{L}$ of various concentrations of sample were mixed with $180 \mu \mathrm{L}$ of ABTS radical solution. After $1 \mathrm{~min}$ incubation at room temperature, the absorbance was measured at $732 \mathrm{~nm}$ and used to calculate the $\mathrm{RC}_{50}$ value. The experiment was performed in triplicate.

\section{Total Phenolics}

The total polyphenol content of the extract and the fractions was determined using the Folin-Denis method [17] adapted to 96-well plates. In each well of a 96-well plate, 60 $\mu \mathrm{L}$ of sample dissolved in distilled water was mixed with 60 $\mu \mathrm{L}$ of 2 -fold diluted Folin reagent. After $3 \mathrm{~min}, 60 \mu \mathrm{L}$ of aqueous $10 \% \quad \mathrm{Na}_{2} \mathrm{CO}_{3}$ was added, and the mixture was mixed and allowed to stand at room temperature in the dark for $1 \mathrm{~h}$. The absorbance was read at $700 \mathrm{~nm}$, and the total polyphenol concentration was calculated from a calibration curve generated using tannic acid as a standard. The results were expressed as $\mathrm{mg} / \mathrm{L}$ of tannic acid equivalents.

\section{Total Flavonoid Content}

The total flavonoid content of the samples was determined using a previously described colorimetric method [17] with some modification. A $0.1-\mathrm{mL}$ sample of 10 -fold diluted solutions in $80 \%$ ethanol was mixed with $20 \mu \mathrm{L}$ of $10 \%$ $\mathrm{Al}\left(\mathrm{NO}_{3}\right)_{3}, 20 \mu \mathrm{L}$ of $1 \mathrm{M} \mathrm{CH}_{3} \mathrm{COOK}$, and $860 \mu \mathrm{L}$ of $80 \%$ ethanol. After $40 \mathrm{~min}$ reaction at room temperature, the increase in absorbance was measured at $415 \mathrm{~nm}$. The total flavonoid content was calculated by comparison with a calibration curve generated using quercetin as a standard. The results were expressed as $\mathrm{mg} / \mathrm{L}$ of quercetin equivalents.

\section{Preparation of Washed Platelets}

Male Sprague-Dawley rats (200 to $250 \mathrm{~g}$ ) were purchased from OrientBio (Orient Bio INC, Korea) and housed in an air-conditioned room that was kept at $21 \pm 2^{\circ} \mathrm{C}$. Blood was collected from the abdominal aorta using plastic syringes containing $0.15 \mathrm{M}$ sodium citrate $(1: 9 \mathrm{v} / \mathrm{v})$ as an anticoagulant. Platelet-rich plasma was obtained after centrifugation of the blood at $120 \times \mathrm{g}$ for $10 \mathrm{~min}$, and washed platelets were prepared as described previously [18]. Briefly, plateletrich plasma was centrifuged at $200 \times \mathrm{g}$ for $15 \mathrm{~min}$ at room temperature, and the sedimented platelet pellets were washed twice with modified Tyrode-HEPES buffer $(137 \mathrm{mM} \mathrm{NaCl}$, $2.9 \mathrm{mM} \mathrm{KCl}, 1 \mathrm{mM} \mathrm{MgCl}, 5 \mathrm{mM}$ glucose, $12 \mathrm{mM} \mathrm{Na}-$ $\mathrm{HCO}_{3}, 0.34 \mathrm{mM} \mathrm{Na}_{2} \mathrm{HPO}_{4}, 20 \mathrm{mM}$ HEPES, and $0.25 \%$ bovine serum albumin, $\mathrm{pH}$ 7.4) containing $1 \mathrm{mM}$ EDTA. Finally, the platelets were gently resuspended in TyrodeHEPES buffer, counted using a cell counter (Hema-vet HV950FS; Drew scientific, Oxford, CT, USA), and adjusted to a concentration of $3 \times 10^{8}$ platelets $/ \mathrm{mL}$.

\section{Platelet Aggregation}

Platelet aggregation experiments were performed with $0.5 \mathrm{~mL}$ of washed platelet suspension in polystyrene cuvettes using a turbidimetric aggregometer (Chrono-log Co., Ltd., Havertown, PA. USA). The washed platelet suspensions were incubated at $37^{\circ} \mathrm{C}$ for $3 \mathrm{~min}$ in the aggregometer with stirring at $1,100 \mathrm{rpm}$. The platelets were then stimulated with $\mathrm{ADP}$ and collagen. Platelet aggregation was monitored as the change in light transmission for $7 \mathrm{~min}$ and the rates were calculated at $5 \mathrm{~min}$ point. The anti-aggregation effects of the samples were tested by preincubation of the washed platelets with samples for $2 \mathrm{~min}$ before the addition of the stimulating agents.

\section{Platelet Adhesion}

Adhesion of activated platelets to fibrinogen and collagen was determined as described by Tuszynski and Murphy [19]. The platelets were preincubated for $10 \mathrm{~min}$ at $37^{\circ} \mathrm{C}$ with test samples at a final concentration of 10, 25, 50, 100, and 200 $\mu \mathrm{g} / \mathrm{mL}$ or without test sample (control) and then activated with $0.2 \mathrm{U} / \mathrm{mL}$ thrombin. Wells of a 96-well microtiter plate were incubated for 2 to $3 \mathrm{~h}$ with $50 \mu \mathrm{L}$ of $2 \mathrm{mg} / \mathrm{mL}$ fibrinogen in PBS ( $\mathrm{pH} 7.5$ ) or $40 \mu \mathrm{g} / \mathrm{mL}$ collagen dissolved in $0.05 \% \mathrm{CH}_{3} \mathrm{COOH}$. The solution was removed by aspiration, incubated for $1 \mathrm{~h}$ with $200 \mu \mathrm{L}$ of PBS containing $1 \%$ bovine serum albumin, and then washed three times with $200 \mu \mathrm{L}$ of PBS. Immediately after washing, $50 \mu \mathrm{L}$ of $0.2 \mathrm{U} / \mathrm{mL}$ thrombin in PBS was added to each well, followed by $100 \mu \mathrm{L}$ of platelet suspension. After $1 \mathrm{~h}$ incubation at $37^{\circ} \mathrm{C}$, nonadherent cells were removed by aspiration, and the wells were 
washed three times with $200 \mu \mathrm{L}$ of PBS. The total cellassociated protein was determined by dissolving the attached platelets in $200 \mu \mathrm{L}$ of bicinchoninic acid working solution (Sigma) for $1 \mathrm{~h}$ at $37^{\circ} \mathrm{C}$. After cooling to room temperature, the absorbance of each well was determined at $562 \mathrm{~nm}$ with a Spectramax 340 microplate reader (Molecular Devices, Sunnyvale, CA, USA).

\section{Statistical Analysis}

All the results are expressed as means \pm SEM or SD, and the significance of differences between the means of two groups was determined using an unpaired Student's $t$-test. The differences were considered significant when $P$ was less than 0.05 . All the experiments were performed at least three times.

\section{RESULTS AND DISCUSSION}

Increasing epidemiological evidence indicates that a diet rich in polyphenols is associated with reduced mortality due to cardiovascular disease [9] and stroke [20]. There is an obvious hypothesis about the antioxidant properties of polyphenols protecting blood vessels against the effects of oxidative stress associated with cardiovascular risk factors. The polyphenolic compounds from red wine and green tea, for example, have been shown to prevent atherosclerosis in animal models $[21,22]$. Thus, we first tested the anti-oxidative activities of various fractions from SMB on platelet function.

\section{DPPH and ABTS Radical-Scavenging Activities}

We examined the antioxidant activities of the methanol extract and the solvent fractions of SMB by measuring their abilities to transfer hydrogen to the stable free radicals DPPH and ABTS. In these experiments, BHA and trolox were used as control compounds, respectively. The tested samples reacted with DPPH, causing a decrease in the absorbance at $517 \mathrm{~nm}$. We also examined the reduction of ABTS free radicals by measuring the absorbance at $732 \mathrm{~nm}$. These methods are commonly used for the screening of antioxidant activity and can be applied to both lipophilic and hydrophilic antioxidants. The radical-scavenging activities, as indicted by their $\mathrm{RC}_{50}$ values, differed between the methanol extract and the various solvent fractions (Table 1), and the scavenging activity increased in a concentrationdependent manner for both radical species (data not shown). The results indicate that among the SMB fractions, the EtOAc fraction was the most potent scavenger of DPPH free radicals $\left(\mathrm{RC}_{50}=2.4 \pm 1.5 \mu \mathrm{g} / \mathrm{mL}\right)$. This was approximately two-fold more potent than the synthetic antioxidant BHA $\left(\mathrm{RC}_{50}=5.5 \pm 0.1 \mu \mathrm{g} / \mathrm{mL}\right)$. The methanol extract and the butanol fractions also exhibited lower $\mathrm{RC}_{50}$ values, indicating better radical-scavenging activity than BHA, whereas the hexane, chloroform, and water fractions had higher $\mathrm{RC}_{50}$ values and, thus, relatively low activity. Furthermore, the EtOAc fraction was the strongest antioxidant amongst the various SMB fractions in the ABTS assay system, with an $\mathrm{RC}_{50}$ of $27.9 \pm 1.4 \mu \mathrm{g} / \mathrm{mL}$. The $\mathrm{RC}_{50}$ of trolox was found to be $18.6 \pm 0.3 \mu \mathrm{g} / \mathrm{mL}$ under the same condition (Table 1). These results along with those from the DPPH assay confirm that some constituents in the EtOAc fraction from SMB have radical scavenging activity.

Lin et al. [23] reported that salvianolic acid B, a watersoluble polyphenolic antioxidant from SMB, exhibits DPPH radical-scavenging activity. The EtOAc fraction of this plant was also reported to potently induce cell death and dopamine release in PC12 cells [24] and to inhibit matrix metalloproteinase- 9 activity and the migration of human aortic smooth muscle cells [25]. Along with these reports, our results suggest that the EtOAc fraction contains highly concentrated antioxidants that have a variety of beneficial effects on human health.

\section{Total Polyphenolic and Flavonoids Content}

Because the antioxidative activities of the methanol extract and the solvent fractions of SMB differed, we determined the total polyphenol and flavonoid contents to identify correlations between the various antioxidant compounds and the antioxidant activity. Table 2 shows the polyphenol and flavonoid contents in the methanol extract and the solvent

Table 1. $\mathrm{RC}_{50}$ Values of SMB Extract and Its Solvent Fractions

\begin{tabular}{|l|c|c|}
\hline \multirow{2}{*}{ Sample $^{\mathbf{b}}$} & \multicolumn{2}{|c|}{ RC $_{\mathbf{5 0}}(\mathbf{m g} / \mathbf{m L})^{\mathbf{a}, \mathbf{c}}$} \\
\cline { 2 - 3 } & DPPH scavenging & $54.7 \pm 3.5$ \\
\hline \hline Methanol extract & $8.6 \pm 0.7$ & $113.2 \pm 19.1$ \\
\hline Hexane fraction & $68.2 \pm 7.1$ & $80.3 \pm 3.2$ \\
\hline Chloroform fraction & $54.7 \pm 3.2$ & $27.9 \pm 1.4$ \\
\hline EtOAc fraction & $2.4 \pm 1.5$ & $35.8 \pm 3.8$ \\
\hline Butanol fraction & $5.1 \pm 0.1$ & $110.9 \pm 21.7$ \\
\hline Water fraction & $46.9 \pm 3.0$ & $18.61 \pm 0.3$ \\
\hline Trolox $^{\mathrm{d}}$ & - & - \\
\hline BHA $^{\mathrm{e}}$ & $5.5 \pm 0.1$ & \\
\hline
\end{tabular}

${ }^{\mathrm{a}}$ Concentration required for $50 \%$ reduction of DPPH $(0.15 \mathrm{mM})$ or ABTS $(7 \mathrm{mM})$ radicals

${ }^{\mathrm{b}}$ Sample concentration is $100 \mu \mathrm{g} / \mathrm{mL}$.

${ }^{\mathrm{c}}$ Values are means \pm SEM $(\mathrm{n}=5)$.

${ }^{\mathrm{d}}$ Standard compound for ABTS assay.

${ }^{\mathrm{e}}$ Standard compound for DPPH assay. 
Table 2. Total Content of Polyphenols and Flavonoids in Solvent Fractions from SMB

\begin{tabular}{|l|c|c|}
\hline & Polyphenols $^{\mathbf{b}}$ & Flavonoids $^{\mathbf{c}}$ \\
\hline \hline Methanol extract & $84.5 \pm 4.5$ & $4.0 \pm 0.3$ \\
\hline Hexane fraction & $54.3 \pm 3.6$ & $37.4 \pm 1.3$ \\
\hline chloroform fraction & $54.7 \pm 7.6$ & $14.0 \pm 0.8$ \\
\hline EtOAc fraction & $578.3 \pm 42.7$ & $29.4 \pm 1.3$ \\
\hline Butanol fraction & $251.3 \pm 11.1$ & $5.2 \pm 1.1$ \\
\hline Water fraction & $60.9 \pm 7.7$ & $1.3 \pm 0.1$ \\
\hline
\end{tabular}

${ }^{\mathrm{a}}$ Values are means $\pm \mathrm{SD}(\mathrm{n}>3)$.

${ }^{\mathrm{b}} \mathrm{mg}$ of total polyphenol content/g of plant based on tannic acid as standard.

${ }^{\mathrm{c}} \mathrm{mg}$ of total flavonoid content/g of plant based on quercetin as standard.

fractions. The polyphenol content was $578.3 \pm 42.7 \mathrm{mg} / \mathrm{mL}$ in the EtOAc fraction. This was the highest concentration and was approximately 7 -fold higher than that in the methanol extract $(84.5 \pm 4.5 \mu \mathrm{g} / \mathrm{mL})$. The polyphenol content decreased in the order of butanol fraction>methanol extract>water fraction>chloroform fraction $>$ hexane fraction. On the other hand, the flavonoid content in the methanol extract was much lower than in the EtOAc or chloroform fraction.

The results in Tables $\mathbf{1}$ and $\mathbf{2}$ reveal a trend for an increase in radical scavenging capacity with the increase in polyphenol content. This agrees with the fact that polyphenolic compounds are responsible for much of the antioxidant capacity of plants.

\section{Platelet Aggregation}

We next examined the inhibitory effects of various fractions obtained from the methanol extract of SMB on the aggregation of washed rat platelets induced by ADP $(6 \mu \mathrm{M})$ or collagen $(2 \mu \mathrm{g} / \mathrm{mL})$ (Table 3$)$.

In these experiments, the fractions were tested at concen- trations of 100 and $50 \mu \mathrm{g} / \mathrm{mL}$, respectively. The EtOAc fraction was a much more potent inhibitor of both ADP- and collagen-induced platelet aggregation compared to the methanol extract, butanol fraction, and water fraction. Pretreatment of platelets with the EtOAc fraction for $2 \mathrm{~min}$ dose-dependently inhibited ADP- and collagen-induced platelet aggregation (Fig. 1), with $\mathrm{IC}_{50}$ values of $34.2 \pm 5.6$ and $25.3 \pm 1.5 \mu \mathrm{g} / \mathrm{mL}$, respectively (Table 4 ).

These results suggest that the ability of the EtOAc fraction to block ADP- or collagen-induced platelet aggregation was significantly increased by fractionation of the methanol extract. This may be due to the concentration of polyphenolic compounds in the EtOAc fraction. The results also show that higher concentrations of the methanol extract and the EtOAc fraction were needed to inhibit ADP-induced aggregation than collagen-induced aggregation. In contrast, the hexane and chloroform fractions induced platelet aggregation in the absence of added agonist; therefore, they were not examined in the aggregation test. On the basis of the results in Fig. (1) and Table 1, we conclude that free radicals

Table 3. Effects of Methanol Extract and Various Fractions Obtained from SMB on Platelet Aggregation Induced by ADP and Collagen

\begin{tabular}{|c|c|c|c|c|}
\hline \multirow{2}{*}{ Sample $^{\mathrm{a}}$} & \multicolumn{2}{|c|}{$\operatorname{Aggregation}(\%)^{\mathbf{b}}$} & \multicolumn{2}{|c|}{ Inhibition $(\%)^{\mathrm{c}}$} \\
\hline & $\mathbf{A D P}^{\mathrm{d}}$ & Collagen $^{\mathrm{e}}$ & ADP & Collagen \\
\hline Methanol extract & $62.3 \pm 3.1$ & $32.3 \pm 4.0$ & 21.7 & 57.5 \\
\hline Hexane fraction & $N D^{f}$ & ND & ND & ND \\
\hline EtOAc fraction & $16.3 \pm 2.3$ & $6.7 \pm 1.2$ & 78.3 & 91.2 \\
\hline Butanol fraction & $40.3 \pm 4.6$ & $16.0 \pm 1.7$ & 46.5 & 79.0 \\
\hline $\mathrm{H}_{2} \mathrm{O}$ fraction & $64.7 \pm 1.5$ & $61.3 \pm 1.5$ & 14.2 & 19.3 \\
\hline
\end{tabular}

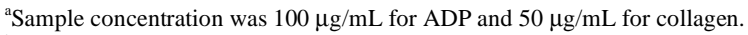

${ }^{\mathrm{b}}$ Aggregation is presented as means \pm SEM $(\mathrm{n}=3)$.

Inhibition $(\%)=[(\mathrm{A}-\mathrm{B}) /(\mathrm{A})] \times 100$, where $\mathrm{A}$ is the percent aggregation in the control and $\mathrm{B}$ is the percent aggregation in the sample $(\%)$.

${ }^{\mathrm{d}}[\mathrm{ADP}]=6 \mu \mathrm{M}$.

[ $[$ Collagen $]=2 \mu \mathrm{g} / \mathrm{mL}$.

${ }^{\mathrm{f}} \mathrm{ND}$, not determined. 

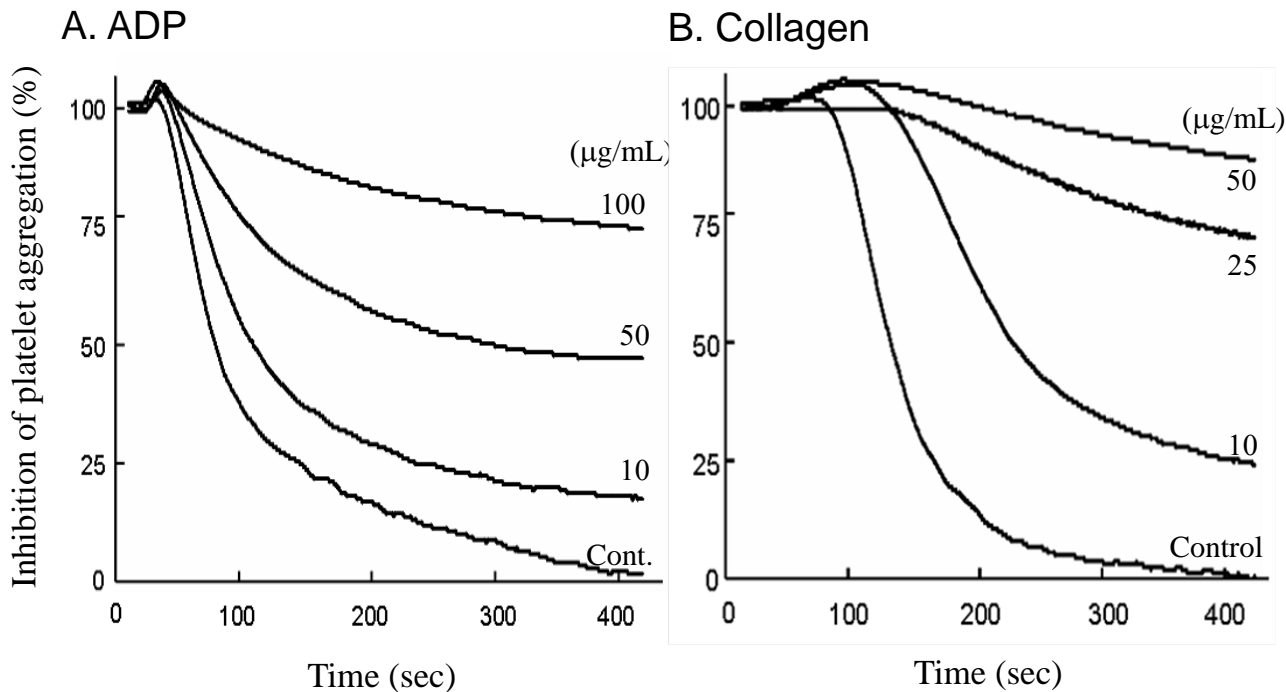

Fig. (1). Effect of EtOAc fraction on rat platelet aggregation induced by ADP or collagen. Washed rat platelets were incubated with sample or DMSO $(0.2 \%)$ at $37^{\circ} \mathrm{C}$ for $2 \mathrm{~min}$ and then stimulated with ADP $(6 \mu \mathrm{M})$ or collagen $(2 \mu \mathrm{g} / \mathrm{mL})$. The extent of aggregation was monitored for 7 min after the addition of an inducer.

Table 4. IC $_{50}$ Values of Methanol Extract and EtOAc Fraction on the Aggregation of Rat Washed Platelets Induced by ADP and Collagen

\begin{tabular}{|l|c|c|}
\hline \multirow{2}{*}{ Agonist } & \multicolumn{2}{|c|}{ IC $_{\mathbf{5 0}}(\mu \mathrm{g} / \mathrm{mL})^{\mathrm{a}}$} \\
\cline { 2 - 3 } & Methanol extract & EtOAc fraction \\
\hline \hline ADP $^{\mathrm{b}}$ & $472.3 \pm 46.5$ & $34.2 \pm 5.6$ \\
\hline Collagen $^{\mathrm{c}}$ & $68.4 \pm 13.2$ & $25.3 \pm 1.5$ \\
\hline
\end{tabular}

${ }^{\mathrm{a}}$ Values are means $\pm \mathrm{SD}(\mathrm{n}=3)$

${ }^{\mathrm{b}}[\mathrm{ADP}]=6 \mu \mathrm{M}$.

${ }^{\mathrm{c}}[$ Collagen $]=2 \mu \mathrm{g} / \mathrm{mL}$.

produced during platelet activation induce platelet aggregation and that bioactive antioxidants in SMB can block this process.

Pignatelli et al. [26] reported that the formation of platelet aggregates is associated with a transient $\mathrm{H}_{2} \mathrm{O}_{2}$ burst, which triggers oxidative stress in platelets. Resveratrol has been shown to inhibit ADP- or thrombin-induced platelet aggregation [27] and secretion [28] and to reduce the production of reactive oxygen species in thrombin-stimulated platelets [29]. In addition, salvianolic acid B, a component of $\mathrm{SMB}$, has been shown to inhibit high shear stress-induced platelet aggregation [30], but the mechanism of action is unclear and whether it is the most potent compound in the polyphenol-rich fraction of this herb is not known.

\section{Platelet Adhesion}

Platelet adhesion mediated by collagen or other adhesive proteins, such as fibrinogen, von Willebrand factor, fibronectin, or vitronectin, is the first step in platelet activation. Interactions between platelet receptors and adhesive proteins mediate platelet adhesion, intracellular signaling, and activation. This is accompanied by the synthesis and release of platelet activators such as thromboxane $\mathrm{A}_{2}$ and ADP [1]. Our results show that the methanol extract and EtOAc fraction of SMB modulate platelet adhesion to colla- gen and fibrinogen. We found that preincubation of rat washed platelets for $10 \mathrm{~min}$ at $37^{\circ} \mathrm{C}$ with 25 to $200 \mu \mathrm{g} / \mathrm{mL}$ of either the methanol extract or the EtOAc fraction dosedependently inhibited the adhesion of platelets to fibrinogen and collagen following stimulation with $0.2 \mathrm{U} / \mathrm{mL}$ thrombin (Fig. 2). The highest concentrations of methanol extract and EtOAc fraction used in the experiments $(200 \mu \mathrm{g} / \mathrm{mL})$ reduced adhesion by $59 \%$ and $49 \%$, respectively. Furthermore, the EtOAc fraction was substantially more potent than the methanol extract at inhibiting platelet adhesion. The butanol and water fractions had little inhibitory effect on platelet adhesion to both collagen and fibrinogen (data not shown). Platelet adhesion has also been shown to be inhibited by polyphenolic compounds from Yucca schidigera Roezl. bark [31] and resveratrol [32], but this is the first report of an effect of SMB on platelet adhesion. We are currently performing additional studies on the effects of the major phenolic compounds in the EtOAc fraction of SMB on different steps in platelet activation.

\section{CONCLUSIONS}

In the current study, we found that the polyphenol-rich EtOAc fraction of SMB potently inhibits platelet aggregation and adhesion in vitro, possibly due to free radical scavenging. On the basis of our results, we conclude that the EtOAc 


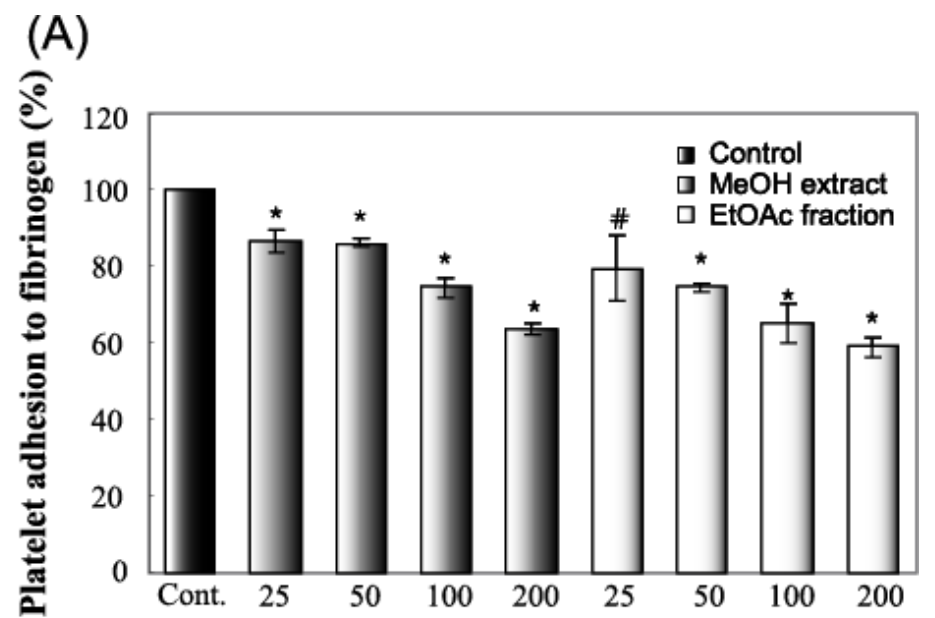

(B)

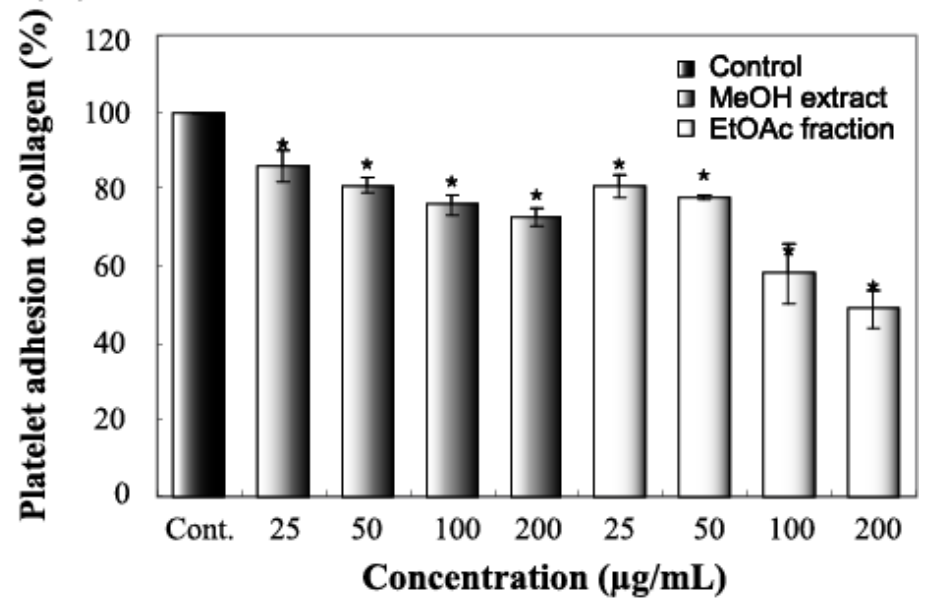

Fig. (2). Effects of the methanol extract and EtOAc fraction on platelet adhesion to fibrinogen or collagen. Washed rat platelets were incubated with sample or DMSO (control; $1 \%$ ) for $10 \mathrm{~min}$ at $37^{\circ} \mathrm{C}$. After incubation, platelets were activated by thrombin $(0.2 \mathrm{U} / \mathrm{mL})$, and the level of adhesion was measured $(\mathrm{n}=3)$. $\# P<0.05 ; * P<0.01$.

fraction of SMB may be an important source of polyphenols with antioxidant activity that can inhibit platelet activation and therefore reduce thrombosis and cardiovascular disease.

\section{ACKNOWLEDGEMENTS}

This research was financially supported by the Ministry of Commerce, Industry and Energy (MOCIE), through the Center for Traditional Microorganism Resources (TMR) at Keimyung University, Republic of Korea, and Korea Industrial Technology Foundation (KOTEF) through the Human Resource Training Project for Regional Innovation.

\section{REFERENCES}

[1] Blockmans, D.; Deckmyn, H.; Vermylen, J. Blood Rev., 1995, 9, 143-156.

[2] Lévy-Toledano, S. Haemostasis, 1999, 29, 4-15.

[3] Mehta, J.L.; Nicolini, F.A.; Donnelly, W.H.; Nichols, W.W. Am. J. Cardiol., 1992, 69, 88-138.

[4] Kim, Y.S.; Pyo, M.K.; Park, K.M.; Park, P.H.; Hahn, B.S.; Wu, S.J.; Yun-Choi, H.S. Thromb. Res., 1998, 91, 33-38.

[5] Rahman, K.; Billington, D. J. Nutr., 2000, 130, 2662-2665.

[6] Srivastava, K.C. Prostaglandins Leukot. Med., 1986, 24, 43-50.

[7] Clubb, F.J.; Schmitz, J.M.; Butler, M.M.; Buja, L.M.; Willerson, J.T.; Campbell, W.B. Arteriosclerosis, 1989, 9, 529-537.

[8] Keevil, J.G.; Osman, H.E.; Reed, J.D.; Folts, J.D. J. Nutr., 2000, 130, 53-56.
[9] Rein, D.; Paglieroni, T.G.; Wun, T.; Pearson, D.A.; Schmitz, H.H.; Gosselin, R.; Keen, C.L. Am. J. Clin. Nutr., 2000, 72, 30-35.

[10] Polette, A.; Lemaitre, D.; Lagarde, M.; Véricel, E. Thromb. Haemost., 1996, 75, 945-949.

[11] Salonen, J.T.; Salonen, R.; Seppänen, K.; Rinta-Kiikka, S.; Kuukka, M.; Korpela, H.; Alfthan, G.; Kantola, M.; Schalch, W. Am. J. Clin. Nutr., 1991, 53, 1222-1229.

[12] Wu, Y.J.; Hong, C.Y.; Lin, S.J.; Wu, P.; Shiao, M.S. Arterioscler. Thromb. Vasc. Biol., 1998, 18, 481-486.

[13] Kim, S.Y.; Moon, T.C.; Chang, H.W.; Son, K.H.; Kang, S.S.; Kim, H.P. Phytother. Res., 2002, 16, 616-620.

[14] Chan, K.; Chui, S.H.; Wong, D.Y.; Ha, W.Y.; Chan, C.L.; Wong, R.N. Life Sci., 2004, 75, 3157-3171.

[15] Moreno, M.I.; Isla, M.I.; Sampietro, A.R.; Vattuone, M.A. J. Ethnophamacol., 2000, 71, 109-114.

[16] Re, R.; Pellegrini, N.; Proteggente, A.; Pannala, A.; Yang, M.; Rice-Evans, C. Free Radic. Biol. Med., 1999, 26, 1231-1237.

[17] Yu, M.H.; Im, H.G.; Lee, H.J.; Ji, Y.J.; Lee, I.S. Korean J. Food Sci. Technol., 2006, 38, 128-134.

[18] Yang, S.A.; Carpenter, C.L.; Abrams, C.S. J. Biol. Chem., 2004 279, 42331-42336.

[19] Tusuzynski, G.P.; Murphy, A. Anal. Biochem., 1990, 184, 189-191.

[20] Truelsen, T.; Gronbaek, M.; Schnohr, P.; Boysen, G. Stroke, 1998, 29, 2467-2472.

[21] Miura, Y.; Chiba, T.; Tomita, I.; Koizumi, H.; Miura, S.; Umegaki, K.; Hara, Y.; Ikeda, M.; Tomita, T. J. Nutr., 2001, 131, 27-32.

[22] Vinson, J.A.; Teufel, K.; Wu, N. Atherosclerosis, 2001, 156, 67-72.

[23] Lin, Y.L.; Wu, C.H.; Luo, M.H.; Huang, Y.J.; Wang, C.N.; Shiao, M.S.; Huang, Y.T. J. Ethnopharmacol., 2006, 105, 215-222. 
[24] Kim, C.H.; Koo, B.S.; Kim, K.O.; Kim, J.K.; Chang, Y.C.; Lee, I.S. Phytother. Res., 2006, 20, 191-199.

[25] Jin, U.H.; Kang, S.K.; Suh, S.J.; Hong, S.Y.; Park, S.D.; Kim, D.W.; Chang, H.W.; Son, J.K.; Lee, S.H.; Son, K.H.; Kim, C.H. Vasc. Pharmacol., 2006, 44, 345-353.

[26] Pignatelli, P.; Pulcinelli, F.M.; Lenti, L.; Gazzaniga, P.P.; Violi, F. Blood, 1998, 91, 484-490.

[27] Zbikowska, H.M.; Olas, B.; Wachowicz, B.; Krajewski, T. Platelets, 1999, 10, 247-252.

[28] Olas, B.; Wachowicz, B.; Szewczuk, J.; Saluk-Juszczak, J.; Kaca, W. Microbios, 2001, 105, 7-13.
[29]

Olas, B.; Wachowicz, B.; Stochmal, A.; Oleszek, W. Nutrition, 2003, 19, 633-640.

[30] Li, M.; Zhao, C.; Wong, R.N.; Goto, S.; Wang, Z.; Liao, F. Clin. Hemorheol. Microcirc., 2004, 31, 97-103.

[31] Olas, B.; Wachowicz, B.; Stochmal, A.; Oleszek, W. Nutrition, 2005, 21, 199-206.

[32] Olas, B.; Wachowicz, B.; Saluk-Juszczak, J.; Zielinski, T. Thromb. Res., 2002, 107, 141-145.

Received: February 27, 2008

Revised: May 05, 2008

Accepted: May 08, 2008

(C) Yang et al.; Licensee Bentham Open.

This is an open access article distributed under the terms of the Creative Commons Attribution License (http://creativecommons.org/licenses/by/2.5/), which permits unrestrictive use, distribution, and reproduction in any medium, provided the original work is properly cited. 